\title{
Vaginal squamous cell carcinoma develops in mice with Arid1a loss and gain of oncogenic Kras
}

\section{Running Title:}

Vaginal squamous cell carcinoma in mice with Arid1a loss and oncogenic Kras

Xiyin Wang ${ }^{1, \#}$, Mariana S. L. Praça ${ }^{1,2,3, \#}$, Jillian R. H. Wendel ${ }^{1}$, Robert E. Emerson ${ }^{4}$, Francesco J. DeMayo ${ }^{5}$, John P. Lydon ${ }^{6}$, Shannon M. Hawkins*1

1Department of Obstetrics and Gynecology, Indiana University School of Medicine, Indianapolis, IN, USA,

${ }^{2}$ Deparment of Obstetrics and Gynecology, Federal University of Minas Gerais, Belo Horizonte, Minas Gerais, Brazil,

${ }^{3}$ Group of Health, Hospital Mater Dei, Belo Horizonte, Minas Gerais, Brazil,

${ }^{4}$ Department of Pathology and Laboratory Medicine, Indiana University School of Medicine, Indianapolis, IN, USA,

${ }^{5}$ National Institute of Environmental Health Sciences, Research Triangle Park, NC, USA,

${ }^{6}$ Department of Molecular and Cellular Biology, Baylor College of Medicine, Houston, TX, USA.

\#Equal contributions

${ }^{*}$ Corresponding author: 
Shannon M. Hawkins, M.D., Ph.D.

Indiana University School of Medicine at

Indiana University Purdue University at Indianapolis (IUPUI)

550 N. University Blvd, UH2440

Indianapolis, IN 46202

Phone: (317) 274-8225

Fax: (317) 944-7417

Email: shhawkin@iu.edu

Conflict of Interest Statement: The authors have no conflict of interest to declare.

Word Count: $\mathbf{3 4 2 8}$

Figure Count: 6

Supplementary Figure Count: 10

Supplementary Table Count: 6 


\section{Abstract:}

Recent sequencing studies showed that loss-of-function mutations in ARID1A (AT-rich interactive domain 1a) were enriched in gynecologic malignancies. However, multiple mouse models with deletion of Arid1a did not exhibit gynecologic malignancy. Oncogenic KRAS mutations are a common finding in endometrial cancers. However, expression of oncogenic Kras $\left(K_{r a s}^{G 12 D}\right)$ in the uterus was not sufficient to develop endometrial cancer. These results suggest that both ARID1A deletion and oncogenic KRAS require additional hits before driving gynecologic malignancy. To determine the role of the combination effects of deletion of Arid1a and oncogenic Kras, Arid1a $a^{\text {flox/flox }}$

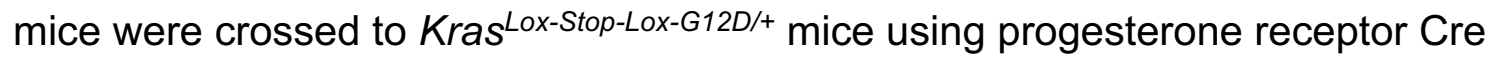
$\left(P g r^{C r e /+}\right)$. Survival studies, histology, and immunohistochemistry were used to characterize the phenotype. Hormone dependence was evaluated by ovarian hormone depletion and estradiol replacement. Arid1a flox/flox; Kras ${ }^{\text {Lox-Stop-Lox-G12D/+; PgrCre/+ }}$ (AKP) mice exhibited early euthanasia due to large vaginal tumors, which were invasive squamous cell carcinoma. Younger mice exhibited precancerous intraepithelial lesions that progressed to invasive squamous cell carcinoma with age. Immunohistochemistry supported the pathological diagnosis with abnormal expression and localization of cytokeratin 5, tumor protein P63, cyclin dependent kinase inhibitor 2A (CDKN2A or p16), and marker of proliferation Ki-67. Vaginal lesions in AKP mice were hormone dependent. Ovarian hormone deletion in AKP mice resulted in atrophic vaginal epithelium without evidence of vaginal tumors. Estradiol replacement in ovarian hormone depleted AKP mice resulted in lesions that resembled the squamous cell carcinoma in intact mice. AKP mice did not develop endometrial cancer. Arid1a deletion 
with $\mathrm{Kras}^{\mathrm{G} 12 D}$ expression drives invasive vaginal squamous cell carcinoma. This mouse can be used to study the transition from benign precursor lesions into invasive vaginal squamous cell carcinoma offering insights into progression.

\section{Keywords (3-10):}

ARID1A, KRAS, vaginal squamous cell carcinoma, mouse model 


\section{INTRODUCTION}

Recent sequencing studies, including both TCGA (The Cancer Genome Atlas) PanCancer and MSK-IMPACT (Memorial Sloan-Kettering Integrated Mutation Profiling and Actionable Cancer Targets) have highlighted potentially impactful mutations across gynecologic cancers [1,2]. Worldwide in 2018 , more than 1.3 million women were diagnosed with a gynecologic cancer, and over 528,000 women with gynecologic cancer died [3]. In silico analyses of multiple, large, publicly-available datasets have shown that a small subset of genes are mutated across uterine cervix, uterine corpus, ovary, vulva, or vagina cancers [4]. However, the functional role of each of these genes in female reproductive tract malignancy remains largely unknown. Further, models of these diseases would improve the understanding of disease pathogenesis, accelerate discovery of novel therapeutics, and improve lives of many women worldwide.

ARID1A (AT-rich interactive domain $1 \mathrm{~A}$ ) was one of eight genes whose mutation frequency was significantly higher in gynecologic malignancies over other cancers [4]. Loss-of-function mutations in $A R I D 1 A$ are frequent in endometriosis-associated ovarian cancers, endometrial cancers, and cervical cancers [1,2,4-11]. More than $40 \%$ of endometrial cancers have a mutation in ARID1A [7-9]. Out of human papilloma virusnegative cervical squamous cell carcinomas, 33\% contained mutations in ARID1A [11]. $A R I D 1 A$ encodes a protein in the switch/sucrose non-fermentable chromatin remodeling complex, playing a role in transcriptional regulation and reprogramming $[9,12,13]$. ARID1A plays an important role in female reproduction and is ubiquitously expressed in the female reproductive tract $[14,15]$. Conditional deletion of Arid1a with the anti- 
Müllerian hormone receptor 2-Cre resulted in subfertility due to abnormal placentation [14]. Conditional deletion of Arid1a with the progesterone receptor-Cre $\left(P g r^{C r e /+}\right)$ or the lactotransferrin-Cre resulted in infertility due to endometrial dysfunction $[15,16]$. Deletion of Arid1a alone in the mouse female reproductive tract was not sufficient to drive cancer. Additional gene deletions were required for development of gynecologic malignancies $[12,13,17]$.

Mutations in KRAS (KRAS proto-oncogene, GTPase) are frequent in gynecologic malignancies, being mutated in more than $10 \%$ of samples across multiple large datasets [4]. Oncogenic KRAS has been detected in up to $30 \%$ of endometrial cancers [18-20]. Increased expression of KRAS was also associated with low overall survival across gynecologic cancers [4]. Conditional expression of $\mathrm{Kras}^{G 12 D}$ alone was insufficient to develop cancer in mice [21-24]. However, Pten (phosphatase and tensin homolog) conditional deletion in $K_{r a s}^{G 12 D}$ expressing mice was sufficient for gynecologic malignancy [22-26]. Similar to deletion of Arid1a alone, gain of oncogenic Kras ${ }^{G 12 D}$ alone in the female reproductive tract was not sufficient to drive cancer and additional gene deletions were required.

Concurrent mutations in both $A R I D 1 A$ and KRAS are frequent in mesonephriclike Müllerian adenocarcinomas of the female reproductive tract [27]. Similarly, concurrent mutations are common in endometrial and cervical cancer, but rarer, yet present, in ovarian cancer $[7,11,28,29]$. We hypothesized that conditional Arid1a 
deletion in $\mathrm{Kras}^{\mathrm{G12D}}$ expressing mice using $\mathrm{Pgr}^{\mathrm{Cre}}$ would generate female reproductive tract cancer.

\section{MATERIALS and METHODS}

\section{Animal husbandry and genotyping}

Animal experiments were approved by the Indiana University School of Medicine Institutional Animal Care and Use Committee following the National Institutes of Health Guide for the Care and Use of Laboratory Animals. All mice were bred and kept under standard conditions. Arid1a $a^{\text {flox/flox }} ; \mathrm{Pgr}^{\mathrm{Cre} /+}[15]$ and $\mathrm{Kras}^{\text {Lox-Stop-Lox-G12D/+ }}$ mice [23] or $\mathrm{Pgr}^{\mathrm{Cre} /+}[30]$ and Kras ${ }^{\text {Lox-Stop-Lox-G12D/+ }}$ mice [23] were crossbred and maintained on a C57BL/6J; 129S5/Brd mixed hybrid background to generate Arid1a flox/flox $_{\text {Kras }}^{\text {Lox-Stop-Lox- }}$ ${ }_{\text {G12D/+;PgrCre/+ }}$ (AKP), Kras ${ }^{\text {Lox-Stop-Lox-G12D/+;PgrCre/+ }}$ (KP), and Pgr ${ }^{+/+}$(control) mice (Supplementary Figure S1). Mice were genotyped at 12-14 days of postnatal life from tail biopsies by PCR as described [14,31,32]. Cre-mediated recombination in Arid1 $a^{\text {flox/flox }}$ mice removes exon 8, leading to loss of protein [33]. Cre-mediated recombination of Kras ${ }^{\text {Lox-Stop-Lox-G12D/+ }}$ mice removes the stop codon, resulting in expression of oncogenic Kras ${ }^{G 12 D}$ [34]. PgrCre/+ drives Cre-mediated recombination where progesterone receptor is expressed [30]. For survival studies, mice were caged, examined twice weekly, and euthanized at humane endpoints [32]. Postmortem tail clips were used to confirm genotyping $[14,31,32]$, and mice with inconsistent genotypes were reassigned or removed.

\section{Histological analyses}


Tissues were fixed, stained, and quantified as described [32]. The Lower Anogenital Squamous Terminology (LAST) project nomenclature was used to describe histology [35]. All histology was interpreted by a surgical pathologist (R.E.E.). Antibodies for immunohistochemistry are listed in Supplementary Table S1. Immunohistochemistry was performed as described [32].

\section{Serum analysis}

Mice were anesthetized by isoflurane (Abbott Laboratories, North Chicago, IL), and blood was collected in microtainer tubes (Becton Dickinson, Franklin Lakes, NJ) by closed cardiac puncture. Serum was separated by centrifugation and stored at $-20^{\circ} \mathrm{C}$ until use. The University of Virginia Ligand Assay and Analysis Core performed measurements of follicle stimulating hormone (FSH) and luteinizing hormone (LH) by radioimmunoassay.

\section{Steroid hormone treatment}

Mice underwent ovariectomy (ov'ex) at six weeks. Mice were randomly divided into treatment groups: estradiol pellet (Innovative Research of America, Sarasota, Florida, $0.25 \mathrm{mg} 17 \beta$-estradiol/60-day release pellet) or no pellet (sham), and tissues collected after 60 days.

\section{Statistical analysis}


Log-rank (Mantel-Cox) test, Fisher's exact test, Student t-test, and multiple t-test was performed using the InStat package for GraphPad Prism 8 (GraphPad, San Diego, CA). $P<0.05$ was considered statistically significant.

\section{RESULTS}

\section{Large vaginal tumors}

Based on criteria for humane endpoints [32], AKP mice showed decreased survival compared to $\mathrm{Pgr}^{+/+}$(Figure 1A and Supplementary Figure S2). The median survival of AKP mice was 106 days. AKP mice (10 of 10 mice) exhibited gross, solid lesions protruding from the vagina, resulting in early euthanasia. These lesions were pink-red, with oblong to round growth on the outer part of the vagina (Figure 1B). Upon dissection, the gross lesions appeared to be confined to the vagina, with grossly normal ovaries, oviducts, and uterus (Figure 1C).

$\mathrm{Pgr}^{+/+}$female mice had normal appearing vaginal histology with well-defined epithelial layers, including a keratinized outer layer of cells without nuclei, stratified squamous epithelium, and lamina propria (Figure 1D). AKP mice showed squamous cell carcinoma with central keratinization surrounded by highly dysplastic squamous epithelium as evidenced by the large, dark nuclei and disorganized cellular pattern, along with nests of cells with abundant eosinophilic cytoplasm (Figure 1E). Additional examples of squamous cell carcinoma are in Supplementary Figure S3, and individual mouse female reproductive tract histology is listed in Supplementary Table S2. 


\section{Early Precancerous Lesions to Cancer}

In women, invasive squamous cell carcinoma develops from precancerous lesions, including low grade squamous intraepithelial lesion (LSIL, also known as vaginal intraepithelial neoplasia 1, VaIN1) or high grade squamous intraepithelial lesion (HSIL, ValN2 and ValN3) [36]. As AKP mice aged, the penetrance of squamous cell carcinoma increased (Figure 2A). Squamous intraepithelial lesions were not found in $\mathrm{Pgr}^{+/+}$mice (Figure 2B). As early as eight weeks, 10\% (1/10) of AKP mice exhibited LSIL. The nuclei in the epithelium were enlarged with variable size, irregular nuclear contours, and increased nuclear-to-cytoplasmic ratios (Figure 2C). Most frequently (7/10), AKP mice at eight weeks had HSIL. The epithelium exhibited a full-thickness proliferation of abnormal parabasal-like cells with loss of maturation and increased nuclear-to-cytoplasmic ratios (Figure 2D). As early as eight weeks, AKP mice (2/10) had invasive squamous cell carcinoma (Figure 2E). Additional magnification views are in Supplementary Figure S4. By 12 weeks, nearly 70\% (16/23) of AKP mice developed squamous cell carcinoma (Figure 2A and Supplementary Table S3). At 16 weeks, 100\% (11/11) AKP mice exhibited squamous cell carcinoma (Figure 2A and Supplementary Table S3).

Because previous studies examined the two-month time point for Kras ${ }^{\text {lox-stop-lox- }}$ G12D/+; PgrCre/+ (KP) mice [24], we examined KP mice for precancerous lesion development. At eight weeks, only one out of six KP mice exhibited HSIL (Supplementary Figure S5 and Supplementary Table S4). The frequency of abnormal 
squamous histology was higher in AKP mice than KP mice at eight weeks (Fisher's exact test $=0.0014, P<0.01)$

\section{Atypical Lesions Outside the Vagina}

$\mathrm{Pgr}^{\mathrm{Cre} /+}$ results in Cre-mediated recombination in the uterus, oviduct, and ovaries [30]. However, no malignancy was identified in the AKP mice besides the vagina. AKP mice had normal ovaries, with normal follicular development (Supplementary Figure S6). Consistent with normal follicular steroid hormone feedback, we observed no significant differences between control and AKP mice in follicle stimulating hormone (FSH) levels (Pgr/+: $3.607 \pm 0.363$ ng/ml, $\mathrm{n}=10 ;$ AKP: $4.952 \pm 1.857$ ng/ml, $\mathrm{n}=10$; unpaired, two-tailed Student t-test, $P=0.487)$ or luteinizing hormone $(\mathrm{LH})$ levels $\left(P g r^{+/+}\right.$: $0.230 \pm 0.060 \mathrm{ng} / \mathrm{ml}, \mathrm{n}=12 ;$ AKP: $0.200 \pm 0.031 \mathrm{ng} / \mathrm{ml}, \mathrm{n}=10 ;$ unpaired, two-tailed Student t-test, $P=0.666)$.

Infrequently (5/14 mice), the oviductal epithelium in AKP mice at 16 weeks contained atypical epithelium with nuclear stratification and multiple layers of epithelial cells with nuclear atypia in the form of nuclear enlargement and rounding (Supplementary Figure S6 and Supplementary Table S3). There was no difference in body weight between AKP and $\mathrm{Pgr}^{+/+}$mice at any time points (data not shown). Uterine weight per body weight in AKP mice at 16 weeks was heavier than control (AKP: $4.2+/-$ $0.29 \mathrm{mg} / \mathrm{g}$; control: $3.2+/-0.29 \mathrm{mg} / \mathrm{g}$; multiple t-test, $P<0.05)$, but there was no significant difference in uterine weight at 12 weeks (AKP: $3.5+/-0.25 \mathrm{mg} / \mathrm{g} ; \mathrm{Pgr}^{+/+}: 3.4+/-$ $0.35 \mathrm{mg} / \mathrm{g}$; multiple t-test, $P=0.88$ ) or 8 weeks (AKP: $2.9+/-0.16 \mathrm{mg} / \mathrm{g} ; \mathrm{Pgr}^{+/+}: 3.5+/-0.69$ 
$\mathrm{mg} / \mathrm{g}$; multiple t-test, $P=0.28)$. Endometrial hyperplasia was observed in $21 \%(3 / 11)$ AKP mice at 16 weeks with enlarged glands separated by minimal amounts of stroma (Supplementary Figure S7 and Supplementary Table S3). Nuclear atypia was also observed with loss of polarity and rounding of the nuclei (Supplementary Figure S7). Endometrial adenocarcinoma was not observed in AKP mice. There was no squamous cell carcinoma detected in the cervix of AKP mice (Supplementary Table S3).

\section{Molecular Characterization}

Cytokeratin 5 (KRT5) is a useful stain for squamous differentiation [36,37]. The basal epithelial cells of $\mathrm{Pgr}^{+/+}$vagina showed intense perinuclear and moderate cytoplasmic KRT5 expression with little to no staining in the lamina propria (Figure 3A and Supplementary Figure S8). Intense cytoplasmic and perinuclear KRT5 staining was observed throughout the full thickness of the vaginal squamous cell carcinoma nests but sparing the underlying lamina propria (Figure 3A and Supplementary Figure S8).

Intense nuclear staining for the basal epithelial cell marker tumor protein P63 (p63) [38] was demonstrated in the basal layer of the $\mathrm{Pgr}^{+/+}$vagina. Moderately intense nuclear p63 staining was observed across the full thickness of the nests of squamous cell carcinoma in AKP vaginas (Figure 3B and Supplementary Figure S8). Vaginal squamous cell carcinoma in women has been shown to have diffusely positive cyclin dependent kinase inhibitor 2A (CDKN2A also known as p16) staining $[36,39]$. The $\mathrm{Pgr}^{+/+}$ vagina showed low intensity, low frequency nuclear staining for $p 16$ that was limited to the basal layer. Nest of vaginal squamous cell carcinoma in AKP mice showed intense, diffusely positive p16 staining (Figure 3C and Supplementary Figure S8). Marker of 
proliferation ki67 (Ki67) staining in $\mathrm{Pgr}^{+/+}$mice was contained to a mostly single layer of basal epithelium of the vagina. Ki67 staining in AKP mice was shown in multiple layers in nests of squamous cell carcinoma (Figure 3D and Supplementary Figure S8).

\section{Hormone-dependent and estradiol responsive tumors}

Ovaries were removed at six weeks (ov'ex), and AKP and $P g r^{+/+}$mice were examined six weeks later (age $=12$ weeks). Ovarian hormone depleted AKP and $\mathrm{Pgr}^{+/+}$ mice at 12 weeks had zero gross lesions $(n=8)$ (Supplementary Table S5), suggesting that AKP vaginal squamous cell carcinoma may be hormone dependent. To assess hormone responsiveness, ov'ex AKP and ov'ex $\mathrm{Pgr}^{+/+}$mice were treated with a 17 $\beta$ estradiol pellet or sham for 60 days. Both ov'ex $\mathrm{Pgr}^{+/+}$-sham and ov'ex AKP-sham had no gross vaginal or uterine lesions, and the uteri were of grossly smaller size than intact mice (Figure 4; ov'ex Pgr ${ }^{+/+}$-sham: 0.51 +/-0.06 mg/g; ggr $^{+/+}$intact: $3.24+/-0.29$ mg/g; two-tailed Student t-test; $P<0.0001$; and ov'ex AKP-sham: 0.48+/-0.054 mg/g; AKP intact: $4.25+/-0.29$ mg/g; two-tailed Student t-test; $P<0.0001)$. Ov'ex $P g r^{+/+}$-E2 uteri were translucent and cystically dilated, consistent with the edematous effects of estradiol in the uterus, and ov'ex $\mathrm{Pgr}^{+/+}$-E2 mice exhibited no gross vaginal lesions (Figure 4). Ov'ex AKP-E2 uteri did not exhibit the characteristic cystic enlargement of estradiol treatment. Ov'ex AKP-E2 uteri were larger than ov'ex AKP-sham uteri (ov'ex AKP-sham: 0.48+/-0.054 mg/g; ov'ex AKP-E2: 24.6+/-15.2 mg/g; two-tailed Student ttest; $P<0.0001)$. However, the ov'ex AKP-E2 uteri were more similar to AKP-intact uteri in that they appeared smooth and solid. The majority of ov'ex AKP-E2 mice (4 out 6) exhibited exophytic gross vaginal lesions (Figure 4 and Supplementary Table S6). 
Both ov'ex $\mathrm{Pgr}^{+/+}$-sham and ov'ex AKP-sham uteri were smaller than intact uteri (Supplementary Figure S9). Histologically, uteri from AKP intact mice showed endometrial hyperplasia with increased surface area of luminal epithelium, crowding of glandular epithelium, and little stroma between glands (Figure 5 and Supplementary Figure S9 and Supplementary Table S3). Neither ov'ex $\mathrm{Pgr}^{+/+}$-sham nor ov'ex AKPsham showed any evidence of endometrial hyperplasia. Both contained a single layer of benign luminal epithelium and normal number of endometrial glands without evidence of atypia (Figure 5 and Supplementary Figure S9 and Supplementary Table S6).

Ov'ex $\mathrm{Pgr}^{+/+}$mice treated with $17 \beta$-estradiol for 60 days (ov'ex $\mathrm{Pgr}^{+/+}$-E2) showed edematous, enlarged uteri. Clear fluid resulted in dilated lumina. The luminal epithelium existed in a single layer that maintained polarity without evidence of nuclear atypia (Figure 5 and Supplementary Figure S9). Ov'ex AKP-E2 uteri were not dilated by fluid. Instead, they were largely lined by epithelium with squamous metaplasia without evidence of adenocarcinoma or nuclear atypia (Figure 5 and Supplementary Figure S9). Other non-malignant phenotypes included endometrial hyperplasia (1/6 mice) and stump pyometra (2/6 mice) (Supplementary Table S6). The hyperplasia and metaplasia seen in ov'ex AKP-E2 mice (4/6) was more penetrant than the hyperplasia observed in intact 16-week mice (3/11).

The vaginal tissue was also hormone responsive. Histologically, hormone depletion in $\mathrm{Pgr}^{+/+}$vaginas (ov'ex $\mathrm{Pgr}^{+/+}$-sham) resulted in a thin single epithelial layer, 
with decreased keratinization (Figure 6 and Supplementary Figure S10), consistent with models of vaginal atrophy in rodents [40]. Treatment with $17 \beta$-estradiol pellets for 60 days (ov'ex $\mathrm{Pgr}^{+/+}$-E2) reversed these effects similar to previous studies [40]. Ov'ex $\mathrm{Pgr}^{+/+}$-E2 vaginas exhibited normal keratinized stratified squamous epithelium and normal lamina propria (Figure 6 and Supplementary Figure S10). Similarly, ov'ex-AKPsham vaginas exhibited a thin layer of vaginal epithelium although it appeared more than a single layer. Treatment with estradiol reversed the benign, atrophic vaginal histology in the ov'ex AKP vaginas to squamous cell carcinoma (Figure 6 and Supplementary Figure S10). Histological description of each animal can be found in Supplementary Table S6.

\section{DISCUSSION}

A small subset of mutated genes are enriched in female reproductive tract malignancies [4], but the functional role of each gene is unclear. To study two such genes, we created the AKP mouse. In our study, AKP mice develop highly penetrant, hormone-responsive squamous cell carcinoma in the vagina. Of note the vaginal squamous cell carcinoma described here is human papillomavirus-(HPV) independent. Importantly, TCGA studies showed that HPV-independent cervical cancer may have $\sim 6 \%$ KRAS mutations and $30 \%$ have loss-of-function mutations in ARID1A [11]. Therefore, this model potentially represents a unique molecular subset of vaginal squamous cell carcinoma. 
Because the PgrCre mouse is a powerful Cre recombinase for endometrial cancer modeling [41], our original hypothesis was that AKP female mice would develop endometrial cancer. Oncogenic KRAS has been detected in up to $30 \%$ of endometrial cancers [18-20]. More than $40 \%$ of endometrial cancers have a mutation in ARID1A [79]. Loss of a proposed tumor suppressor and gain of an oncogene in the uterus should have led to endometrial cancer. The aggressive nature of the vaginal tumors leading to early euthanasia for humane reasons may explain the malignancy limited to the vagina rather than the endometrium. By 16 weeks AKP mice had highly aggressive vaginal tumors limiting the ability to study other gynecological malignancies that may develop at older time points. To support this notion, the hyperplasia and epithelial cell squamous metaplasia seen in ov'ex AKP-E2 mice (4/6) was more penetrant than the hyperplasia observed in intact 16-week AKP females (3/11). However, even with long-term (60 day) $17 \beta$-estradiol treatment, endometrial cancer was not discovered, suggesting that something molecular may be restraining cancer in the endometrium rather than the vagina. Similarly, in the pancreatic cancer field, oncogenic Kras was found to be insufficient to drive pancreatic adenocarcinoma due to the protective effects of ARID1A [42-47]. For example, oncogenic expression of $\mathrm{Kras}^{G 12 D}$ alone leads to pancreatic intraepithelial lesions but not malignancy. Following a loss of function mutation in Arid1a, the $\mathrm{Kras}^{G 12 D}$-expressing mice developed pancreatic ductal adenocarcinoma. These studies all support the hypothesis that ARID1A restrains malignant transformation from benign lesions driven by oncogenic Kras ${ }^{G 12 D}$. Work in pancreatic adenocarcinoma [42-47] has identified escape mechanisms that need to be explored in the endometrium. 
Mechanistically, the early development of aggressive and highly penetrant vaginal tumors may be in part due to the suppression of oncogenic-induced cellular senescence mediated by ARID1A loss. Cellular senescence plays a vital role in vaginal development; in fact, when senescence is blocked during murine development mice generate septate vaginas [48]. Cellular senescence is frequently found in aging or cancerous tissue, potentially due to oncogenic signaling [49]. Oncogenic KRAS ${ }^{\mathrm{G} 12 \mathrm{D}}$ expression in pancreatic cancer cell lines induces cellular senescence [47]. Of note, ARID1A knockdown repressed oncogenic-induced cellular senescence in KRAS ${ }^{\mathrm{G} 12 \mathrm{D}}$ pancreatic cell lines, leading to cell cycle progression [47]. Thus, we posit that deletion of Arid1a with gain of oncogenic Kras ${ }^{G 12 D}$ leads to loss of oncogene-induced cellular senescence and unchecked proliferation and malignant transformation. Consistent with this view, ARID1A promoter hypermethylation and decreased ARID1A expression led to increase progression of squamous cell carcinoma in vitro and in vivo [50]. CDKN2A or p16 is potential marker of cellular senescence. Specifically, p16 staining was found, as expected [36,39], in the $\mathrm{Pgr}^{+/+}$mouse localized to the nucleus. The AKP vaginal squamous cell carcinoma expressed p16 in both the nucleus and the cytoplasm (Figure 3). Cytoplasmic p16 staining was previously considered an artifact, although there is evidence that cytoplasmic staining is tumor specific $[51,52]$. In fact, it was hypothesized that cytoplasmic staining represents the cellular mechanism in which p16 becomes inactivated and allows for tumor progression [51,52]. Cytoplasmic p16 has been studied as a potential prognostic marker in squamous cell carcinoma of the head and neck, with increased survival correlating with higher cytoplasmic staining [53-55]. Both the 
functional role of oncogenic cellular senescence in vaginal squamous cell carcinoma development and the mechanistic role of Arid1a in the translocation of p16 need further investigation.

In humans, Kras mutations were not found in vaginal squamous cell carcinoma [4], but Kras ${ }^{G 12 D-i n d u c e d ~ v a g i n a l ~ l e s i o n s ~ h a v e ~ b e e n ~ p r e v i o u s l y ~ r e p o r t e d ~ i n ~ m i c e ~}[24,56]$. Kim et al. and Gades et al. both reported vaginal papilloma when $\mathrm{Kras}^{G 12 D}$ was mutated through a progesterone or insulin promoter factor mediated-Cre. These lesions had high penetrance but were non-malignant $[24,56]$. Their benign nature suggests that a secondary hit may be necessary for transformation to malignancy. This hypothesis is supported by the presence of vaginal squamous cell carcinoma in $K r a s^{G 12 D}$ mice with a Pten inactivating mutation driven by vaginal delivered adenovirus-Cre [25]. Blum et al. described the vaginal lesions as exophytic protruding externally from the vagina and histologically resembled those described here in AKP mice [25]. Similarly, AKP female mice exhibited vaginal tumors that were malignant earlier (Figure 2) than KP female mice developed non-malignant lesions [24].

The effects of $17 \beta$-estradiol treatment on tumor growth were surprising. Clinically, vaginal squamous cell carcinoma is not treated as a hormone-responsive disease. While clinically $17 \beta$-estradiol is used to increase epithelial cell thickness and treat the symptoms associated with postmenopausal vaginal atrophy, the mechanisms involved in squamous cell proliferation and differentiation are not well studied. Further, the 
effects of $17 \beta$-estradiol treatment on progesterone receptor expression and thus, function of Cre recombinase in the vagina need further study.

Clinically, 17,600 women were diagnosed with primary vaginal squamous cell carcinoma and 8062 women died from vaginal squamous cell carcinoma worldwide in 2018 [3]. Therefore, the continued development of new models is critical to understanding the mechanistic changes. As the impact of the HPV vaccine decreases the prevalence of HPV-dependent squamous cell carcinoma, this model of HPVindependent squamous cell carcinoma will be even more important. We have described a genetically engineered mouse model that targets the knockout of the tumor suppressor Arid1a and the knock in of oncogenic Kras ${ }^{G 12 D}$ in the gynecologic tract, leading to the development of primary squamous cell carcinoma of the vagina. We describe the progression of disease both within the vagina and benign lesions found outside the vagina. We highlighted the role of hormone expression in primary squamous cell carcinoma of the vagina, alluding to potential mechanistic and therapeutic targets. Finally, we proposed a potential mechanism for tumor progression of repressed oncogenic-induced cellular senescence via translocation of $\mathrm{p} 16$ from the nucleus to the cytoplasm. This genetically engineered mouse model of primary squamous cell carcinoma of the vagina may lead to advances in early detection, understanding of initiation and progression, and novel treatment options.

\section{Acknowledgements}


We thank the Indiana Center for Musculoskeletal Health Histology Core at Indiana University School of Medicine and the Human Tissue and Acquisition and Pathology Core at the Dan L. Duncan Comprehensive Cancer Center at Baylor College of Medicine for histology services, and University of Virginia Center for Research in Reproduction Ligand Assay and Analysis Core for the hormone assay.

The University of Virginia Center for Research in Reproduction Ligand Assay and Analysis Core is supported by the Eunice Kennedy Shriver NICHD Grant R24 HD102061. This work was supported by The Liz Tilberis Scholarship Ovarian Cancer Research Fund through the Estate of Agatha Fort (to S.M.H.), 1R03 CA19127 A1 (to SMH), NIH/NICHD R01 HD042311 (to JPL), and Coordenação de Aperfeiçoamento de Pessoal de Nível Superior -(CAPES) - Brazil (to MSLP). The Intramural Research Program of the National Institute of Environmental Health Sciences supported FJD: Project Z1AES103311-01. We thank Julio Agno for technical support. We thank Dr. Joanne S. Richards for kindly providing the Kras ${ }^{\text {Lox-Stop-Lox-G12D/+ }}$ mice and Dr. Zhong Wang for kindly providing the Arid1 $a^{\text {flox/flox }}$ mice.

\section{Statement of Author Contributions}

$\mathrm{XW}, \mathrm{MP}$, and SMH contributed to study design, data collection, data analysis, data interpretation, literature search, and generation of figures. JRHW contributed to data interpretation, literature search, and generation of figures. REE contributed to data analysis, data interpretation, literature search, and generation of figures. JPL and FJD 
bioRxiv preprint doi: https://doi.org/10.1101/2020.12.15.422959; this version posted December 15, 2020. The copyright holder for this preprint (which was not certified by peer review) is the author/funder. All rights reserved. No reuse allowed without permission.

contributed new reagents/analytic tools. All authors were involved in writing and editing the paper and had final approval of the submitted and published versions. 
Figure legends:

Figure 1. Poor survival and squamous cell carcinoma in AKA female mice. (A) KaplanMeier survival curves were analyzed by log-rank (Mantel-Cox) test. AKP mice have decreased survival compared to control mice. ${ }^{* * *} P<0.001 . n=10$ per group. (B) Gross vaginal tumor burden (white arrow) in AKP mice. (C) Gross lesions were localized to the vagina with grossly normal ovaries, oviducts, uterus, and cervix. Ruler, tick mark indicates $1 \mathrm{~mm}$. (D) Control vagina showed normal keratinized stratified squamous epithelium (SSE) and lamina propria (LP). (E) AKP vagina exhibited squamous cell carcinoma lined by highly dysplastic squamous epithelium (DSE) with central keratinization (star) and nests of cells (dashed circle) with abundant eosinophilic cytoplasm (black arrow). Scale bars, low-power (insets), $200 \mu \mathrm{m}$; high-power, $50 \mu \mathrm{m}$. Hematoxylin and eosin staining.

Figure 2. Squamous intraepithelial lesions and squamous cell carcinoma in AKP mice. (A) Schematic timeline of the progression of squamous intraepithelial lesions to squamous cell carcinoma in AKP mice. At 8 weeks, (B) $P g r^{+/+}$vagina showed normal stratified squamous epithelium (SSE). (C) Ten percent of AKP vaginas contained LSIL with increased nuclear-to-cytoplasmic ratios and loss of maturation (LOM) in the lower epithelium. (D) Seventy percent of AKP vaginas exhibited HSIL with cell crowding, high nuclear-to cytoplasmic ratio, and LOM in at least two-thirds of the epithelium. (E) Twenty percent of AKP vaginas displayed squamous cell carcinoma with nests of cells (dashed circle) and highly dysplastic squamous epithelium invading through the stroma (black arrow). Scale bars, $20 \mu \mathrm{m}$. Hematoxylin and eosin staining. 
Figure 3. Molecular Immunohistochemical staining for (A) cytokeratin 5 (KRT5), (B) tumor protein P63 (p63), (C) cyclin dependent kinase inhibitor 2A (p16), and (D) marker of proliferation Ki-67 (ki67). SSE = stratified squamous epithelium, LP = lamina propria, arrow $=$ basal layer, dashed circle $=$ nests of squamous cell carcinoma. Scale bars, 20 $\mu \mathrm{m}$.

Figure 4. Gross lesions in AKP mice with $17 \beta$-estradiol treatment for 60 days. Intact AKP mice exhibited large gross vaginal lesions. Both ov'ex $P g r^{+/+}$-sham and ov'ex AKPsham mice exhibited tiny, thin uteri without gross vaginal lesions. Ov'ex $\mathrm{Pgr}^{+/+}-\mathrm{E} 2$ mice had enlarged fluid-filled uteri. Ov'ex AKP-E2 mice exhibited gross vaginal lesions but without the edematous cystic nature of the uterus. Ruler, tick mark indicates $1 \mathrm{~mm}$.

Figure 5. Uterine histology in $\mathrm{Pgr}^{+/+}$and AKP mice with and without $17 \beta$-estradiol (E2) treatment. 16-week-old intact $\mathrm{Pgr}^{+/+}$and AKP mouse uteri are shown for comparison. AKP intact uteri shown exhibits endometrial hyperplasia. Ov'ex AKP-sham are similar in histology to ov'ex $\mathrm{Pgr}^{+/+}$-sham. Ov'ex $\mathrm{Pgr}^{+/+}$-E2 exhibited enlarge dilated uteri without evidence of endometrial hyperplasia or atypia. Ov'ex AKP-E2 exhibited squamous metaplasia of the endometrium (black arrow). LE = luminal epithelium. Scale bars, 50 $\mu \mathrm{m}$. Hematoxylin and eosin staining.

Figure 6. Vaginal histology in $\mathrm{Pgr}^{+/+}$and AKP mice with and without $17 \beta$-estradiol (E2) treatment.16-week-old intact $\mathrm{Pgr}^{+/+}$and AKP mouse vaginas are shown for comparison. 
Intact $\mathrm{Pgr}^{+/+}$vaginas exhibited normal keratinized stratified squamous epithelium (SSE) with underlying lamina propria (LP). Intact AKP vaginas show squamous cell carcinoma with central keratinization (star), eosinophilic cytoplasm (arrow), and dysplastic squamous epithelium (DSE). Ov'ex $\mathrm{Pgr}^{+/+}$-sham vaginas exhibited signs of vaginal atrophy with thin atrophic epithelium (AE) and thin lamina propria. Hormone replacement resulted in a thickened epithelial layer with keratinization and normal lamina propria. Ov'ex AKP-sham mice exhibited thinning of vaginal epithelium without evidence of carcinoma. Ov'ex AKP-E2 mice exhibited squamous cell carcinoma with dysplastic squamous epithelium (DSE) and eosinophilic cytoplasm (black arrow). Scale bars, $50 \mu \mathrm{m}$. Hematoxylin and eosin staining. 
bioRxiv preprint doi: https://doi.org/10.1101/2020.12.15.422959; this version posted December 15, 2020. The copyright holder for this preprint (which was not certified by peer review) is the author/funder. All rights reserved. No reuse allowed without permission.

Supplementary Figures document as PDF contains figure legends with supplementary figures.

Supplementary Tables S1-S6 are included in the Excel sheet. 


\section{References}

1. Zehir A, Benayed R, Shah RH, et al. Mutational landscape of metastatic cancer revealed from prospective clinical sequencing of 10,000 patients. Nat Med 2017; 23: 703-713.

2. Hoadley KA, Yau C, Hinoue T, et al. Cell-of-Origin Patterns Dominate the Molecular Classification of 10,000 Tumors from 33 Types of Cancer. Cell 2018; 173: 291-304 e296.

3. Bray F, Ferlay J, Soerjomataram I, et al. Global cancer statistics 2018:

GLOBOCAN estimates of incidence and mortality worldwide for 36 cancers in 185 countries. CA Cancer J Clin 2018; 68: 394-424.

4. Chava S, Gupta R. Identification of the Mutational Landscape of Gynecological Malignancies. J Cancer 2020; 11: 4870-4883.

5. Wiegand KC, Shah SP, Al-Agha OM, et al. ARID1A mutations in endometriosisassociated ovarian carcinomas. N Engl J Med 2010; 363: 1532-1543.

6. Jones S, Wang TL, Shih le M, et al. Frequent mutations of chromatin remodeling gene ARID1A in ovarian clear cell carcinoma. Science 2010; 330: 228-231.

7. Cancer Genome Atlas Research N, Kandoth C, Schultz N, et al. Integrated genomic characterization of endometrial carcinoma. Nature 2013; 497: 67-73.

8. Guan B, Mao TL, Panuganti PK, et al. Mutation and loss of expression of ARID1A in uterine low-grade endometrioid carcinoma. Am J Surg Pathol 2011;

35: 625-632. 
9. Guan B, Wang TL, Shih le M. ARID1A, a factor that promotes formation of SWI/SNF-mediated chromatin remodeling, is a tumor suppressor in gynecologic cancers. Cancer Res 2011; 71: 6718-6727.

10. Jones S, Li M, Parsons DW, et al. Somatic mutations in the chromatin remodeling gene ARID1A occur in several tumor types. Hum Mutat 2012; 33: 100-103.

11. Cancer Genome Atlas Research N, Albert Einstein College of M, Analytical Biological S, et al. Integrated genomic and molecular characterization of cervical cancer. Nature 2017; 543: 378-384.

12. Suryo Rahmanto $\mathrm{Y}$, Shen $\mathrm{W}$, Shi $\mathrm{X}$, et al. Inactivation of Arid1a in the endometrium is associated with endometrioid tumorigenesis through transcriptional reprogramming. Nat Commun 2020; 11: 2717.

13. Wilson MR, Reske JJ, Holladay J, et al. ARID1A and PI3-kinase pathway mutations in the endometrium drive epithelial transdifferentiation and collective invasion. Nat Commun 2019; 10: 3554.

14. Wang X, Khatri S, Broaddus R, et al. Deletion of Arid1a in Reproductive Tract Mesenchymal Cells Reduces Fertility in Female Mice. Biol Reprod 2016; 94: 93.

15. Kim TH, Yoo JY, Wang Z, et al. ARID1A Is Essential for Endometrial Function during Early Pregnancy. PLoS Genet 2015; 11: e1005537.

16. Marquardt RM, Kim TH, Yoo JY, et al. Endometrial epithelial ARID1A is critical for uterine gland function in early pregnancy establishment. Faseb j 2020.

17. Wendel JRH, Wang X, Hawkins SM. The Endometriotic Tumor Microenvironment in Ovarian Cancer. Cancers (Basel) 2018; 10: E261. 
18. Engelsen IB, Akslen LA, Salvesen HB. Biologic markers in endometrial cancer treatment. APMIS 2009; 117: 693-707.

19. Dobrzycka B, Terlikowski SJ, Mazurek A, et al. Mutations of the KRAS oncogene in endometrial hyperplasia and carcinoma. Folia Histochem Cytobiol 2009; 47: 65-68.

20. Kandoth C, McLellan MD, Vandin F, et al. Mutational landscape and significance across 12 major cancer types. Nature 2013; 502: 333-339.

21. Fan HY, Liu Z, Paquet M, et al. Cell type-specific targeted mutations of Kras and Pten document proliferation arrest in granulosa cells versus oncogenic insult to ovarian surface epithelial cells. Cancer Res 2009; 69: 6463-6472.

22. Mullany LK, Fan HY, Liu Z, et al. Molecular and functional characteristics of ovarian surface epithelial cells transformed by KrasG12D and loss of Pten in a mouse model in vivo. Oncogene 2011; 30: 3522-3536.

23. Dinulescu DM, Ince TA, Quade BJ, et al. Role of K-ras and Pten in the development of mouse models of endometriosis and endometrioid ovarian cancer. Nat Med 2005; 11: 63-70.

24. Kim TH, Wang J, Lee KY, et al. The Synergistic Effect of Conditional Pten Loss and Oncogenic K-ras Mutation on Endometrial Cancer Development Occurs via Decreased Progesterone Receptor Action. J Oncol 2010; 2010: 139087.

25. Blum JS, Weller CE, Booth CJ, et al. Prevention of K-Ras- and Pten-mediated intravaginal tumors by treatment with camptothecin-loaded PLGA nanoparticles. Drug Deliv Transl Res 2011; 1: 383-394. 
26. Kun EHS, Tsang YTM, Lin S, et al. Differences in gynecologic tumor development in Amhr2-Cre mice with KRAS(G12D) or KRAS(G12V) mutations. Sci Rep 2020; 10: 20678.

27. Mirkovic J, McFarland M, Garcia E, et al. Targeted Genomic Profiling Reveals Recurrent KRAS Mutations in Mesonephric-like Adenocarcinomas of the Female Genital Tract. Am J Surg Pathol 2018; 42: 227-233.

28. Ishikawa M, Nakayama K, Nakamura K, et al. Affinity-purified DNA-based mutation profiles of endometriosis-related ovarian neoplasms in Japanese patients. Oncotarget 2018; 9: 14754-14763.

29. Hollis RL, Thomson JP, Stanley B, et al. Molecular stratification of endometrioid ovarian carcinoma predicts clinical outcome. Nat Commun 2020; 11: 4995.

30. Soyal SM, Mukherjee A, Lee KY, et al. Cre-mediated recombination in cell lineages that express the progesterone receptor. Genesis 2005; 41: 58-66.

31. Hadji A, Ceppi P, Murmann AE, et al. Death induced by CD95 or CD95 ligand elimination. Cell Rep 2014; $7:$ 208-222.

32. Wang X, Wendel JRH, Emerson RE, et al. Pten and Dicer1 loss in the mouse uterus causes poorly differentiated endometrial adenocarcinoma. Oncogene 2020; 39: 6286-6299.

33. Gao X, Tate P, Hu P, et al. ES cell pluripotency and germ-layer formation require the SWI/SNF chromatin remodeling component BAF250a. Proc Natl Acad Sci U S A 2008; 105: 6656-6661.

34. Johnson L, Mercer K, Greenbaum D, et al. Somatic activation of the K-ras oncogene causes early onset lung cancer in mice. Nature 2001; 410: 1111-1116. 
35. Darragh TM, Colgan TJ, Thomas Cox J, et al. The Lower Anogenital Squamous Terminology Standardization project for HPV-associated lesions: background and consensus recommendations from the College of American Pathologists and the American Society for Colposcopy and Cervical Pathology. Int J Gynecol Pathol 2013; 32: 76-115.

36. Malpica A. Neoplastic Lesions of the Vagina. In: Gynecologic Pathology: A Volume in Foundations in Diagnostic Pathology Series. Second edition ed. Nucci MR, Parra-Herran C, (ed)^(eds). Elsevier: Philadelphia, PA 19103-2899, 2020; 153-184.

37. Moll R, Divo M, Langbein L. The human keratins: biology and pathology. Histochem Cell Biol 2008; 129: 705-733.

38. Kurita T, Cunha GR, Robboy SJ, et al. Differential expression of p63 isoforms in female reproductive organs. Mech Dev 2005; 122: 1043-1055.

39. Bertoli HK, Rasmussen CL, Sand FL, et al. Human papillomavirus and p16 in squamous cell carcinoma and intraepithelial neoplasia of the vagina. Int $J$ Cancer 2019; 145: 78-86.

40. Ceccarelli S, D'Amici S, Vescarelli E, et al. Topical KGF treatment as a therapeutic strategy for vaginal atrophy in a model of ovariectomized mice. Journal of cellular and molecular medicine 2014; 18: 1895-1907.

41. Pandita P, Wang X, Jones DE, et al. Unique Molecular Features in High-Risk Histology Endometrial Cancers. Cancers (Basel) 2019; 11. 
42. Ferri-Borgogno S, Barui S, McGee AM, et al. Paradoxical Role of AT-rich Interactive Domain 1A in Restraining Pancreatic Carcinogenesis. Cancers (Basel) 2020; 12.

43. Livshits G, Alonso-Curbelo D, Morris JPt, et al. Arid1a restrains Kras-dependent changes in acinar cell identity. Elife 2018; 7.

44. Kimura Y, Fukuda A, Ogawa S, et al. ARID1A maintains differentiation of pancreatic ductal cells and inhibits development of pancreatic ductal adenocarcinoma in mice. Gastroenterology 2018; 155: 194-209. e192.

45. Wang SC, Nassour I, Xiao S, et al. SWI/SNF component ARID1A restrains pancreatic neoplasia formation. Gut 2019; 68: 1259-1270.

46. Wang W, Friedland SC, Guo B, et al. ARID1A, a SWI/SNF subunit, is critical to acinar cell homeostasis and regeneration and is a barrier to transformation and epithelial-mesenchymal transition in the pancreas. Gut 2019; 68: 1245-1258.

47. Li ZY, Zhu SS, Chen XJ, et al. ARID1A suppresses malignant transformation of human pancreatic cells via mediating senescence-associated miR-503/CDKN2A regulatory axis. Biochem Biophys Res Commun 2017; 493: 1018-1025.

48. Muñoz-Espín D, Cañamero M, Maraver A, et al. Programmed cell senescence during mammalian embryonic development. Cell 2013; 155: 1104-1118.

49. Campisi J, d'Adda di Fagagna F. Cellular senescence: when bad things happen to good cells. Nat Rev Mol Cell Biol 2007; 8: 729-740.

50. Luo Q, Wu X, Chang W, et al. ARID1A Hypermethylation Disrupts Transcriptional Homeostasis to Promote Squamous Cell Carcinoma Progression. Cancer Res 2020; 80: 406-417. 
51. Evangelou K, Bramis J, Peros I, et al. Electron microscopy evidence that cytoplasmic localization of the p16(INK4A) "nuclear" cyclin-dependent kinase inhibitor (CKI) in tumor cells is specific and not an artifact. A study in non-small cell lung carcinomas. Biotech Histochem 2004; 79: 5-10.

52. Nilsson K, Landberg G. Subcellular localization, modification and protein complex formation of the cdk-inhibitor p16 in Rb-functional and Rb-inactivated tumor cells. Int J Cancer 2006; 118: 1120-1125.

53. Lai S, Wenaas AE, Sandulache VC, et al. Prognostic Significance of p16 Cellular Localization in Oropharyngeal Squamous Cell Carcinoma. Ann Clin Lab Sci 2016; 46: 132-139.

54. Zhao N, Ang MK, Yin XY, et al. Different cellular p16(INK4a) localisation may signal different survival outcomes in head and neck cancer. Br J Cancer 2012;

107: 482-490.

55. Ciesielska U, Zatonski T, Nowinska K, et al. Expression of Cell Cycle-related Proteins p16, p27 and Ki-67 Proliferating Marker in Laryngeal Squamous Cell Carcinomas and in Laryngeal Papillomas. Anticancer Res 2017; 37: 2407-2415.

56. Gades NM, Ohashi A, Mills LD, et al. Spontaneous vulvar papillomas in a colony of mice used for pancreatic cancer research. Comp Med 2008; 58: 271-275. 
A

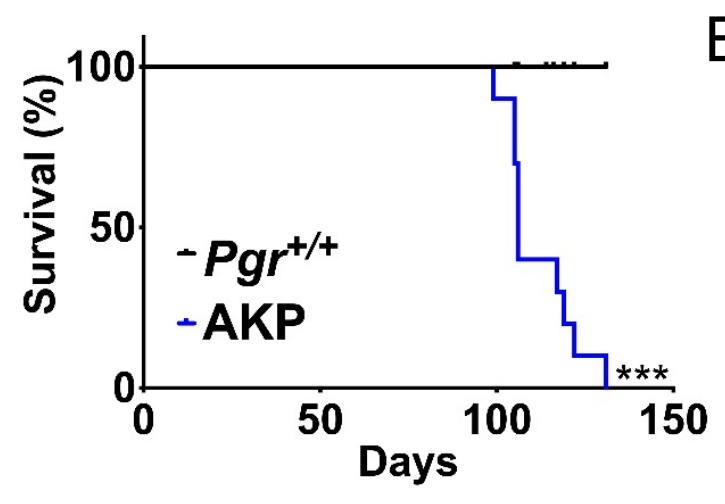

B

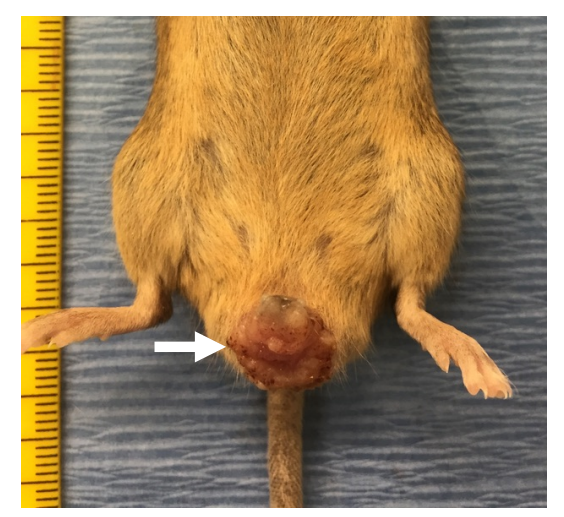

$\mathrm{E}$
$\mathrm{D}$

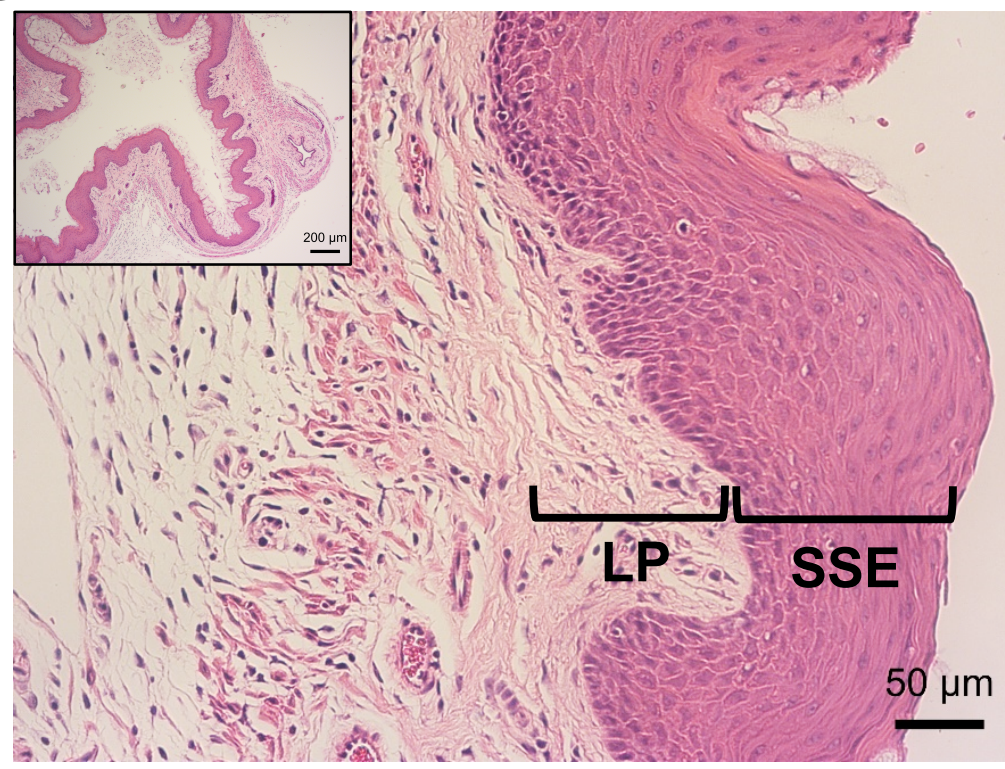

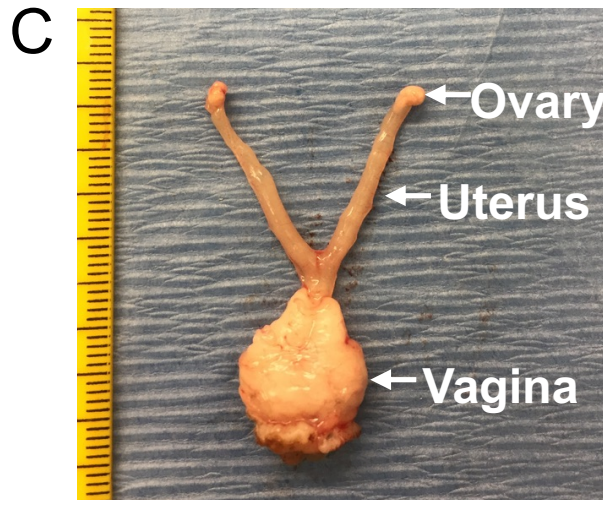

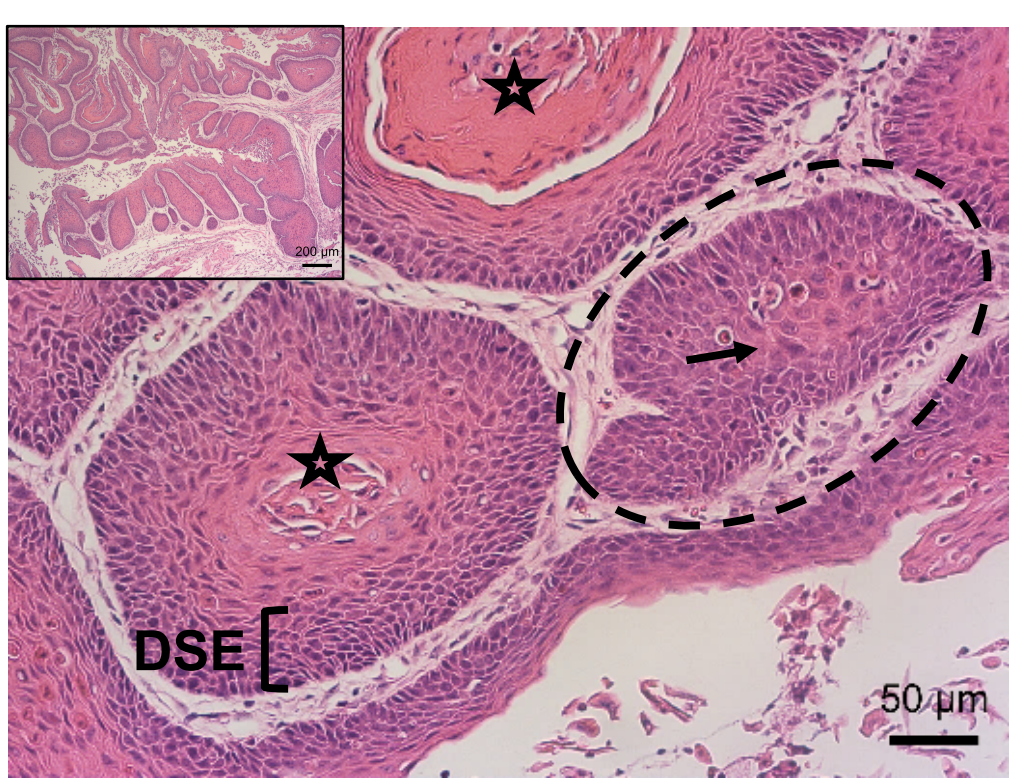

Figure 1. Poor survival and squamous cell carcinoma in AKA female mice. (A) Kaplan-Meier survival curves were analyzed by log-rank (Mantel-Cox) test. AKP mice have decreased survival compared to control mice. ${ }^{* * *} P<$ 0.001. $n=10$ per group. (B) Gross vaginal tumor burden (white arrow) in AKP mice. (C) Gross lesions were localized to the vagina with grossly normal ovaries, oviducts, uterus, and cervix. Ruler, tick mark indicates $1 \mathrm{~mm}$. (D) Control vagina showed normal keratinized stratified squamous epithelium (SSE) and lamina propria (LP). (E) AKP vagina exhibited squamous cell carcinoma lined by highly dysplastic squamous epithelium (DSE) with central keratinization (star) and nests of cells (dashed circle) with abundant eosinophilic cytoplasm (black arrow). Scale bars, low-power (insets), $200 \mu \mathrm{m}$; high-power, $50 \mu \mathrm{m}$. Hematoxylin and eosin staining. 


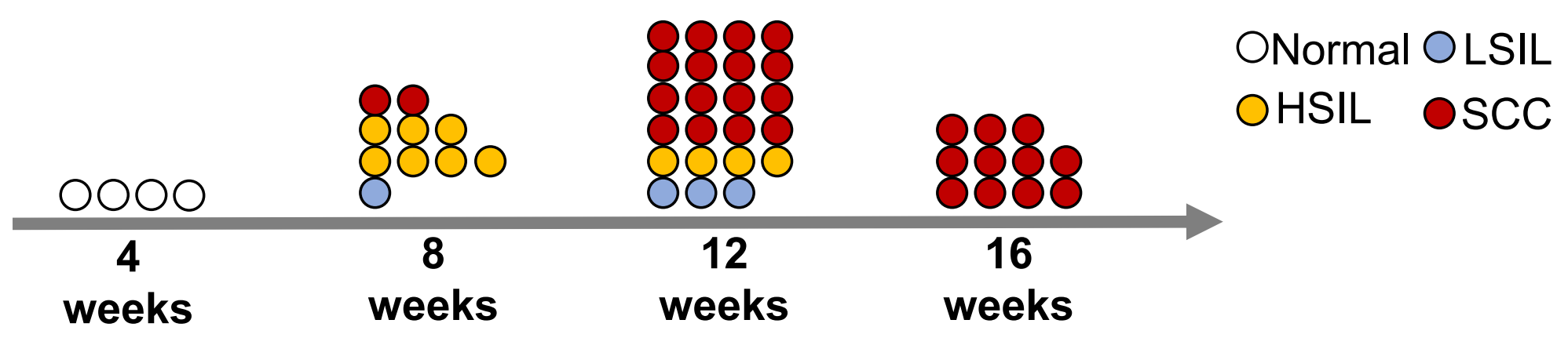

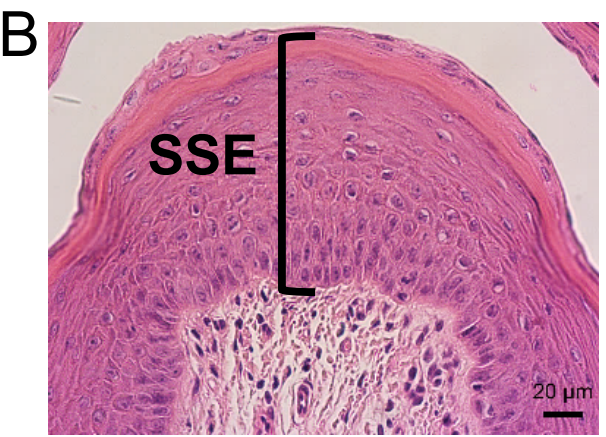

Normal

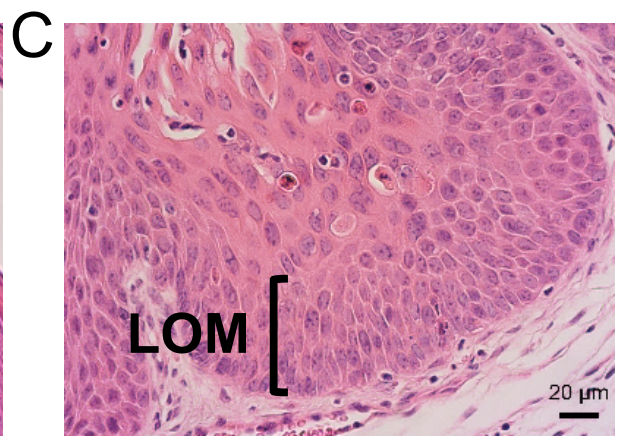

LSIL

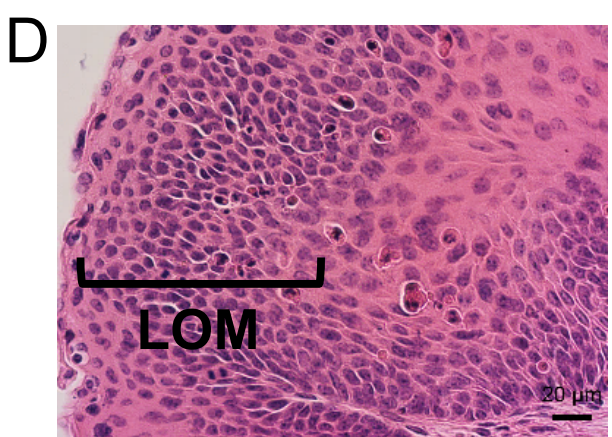

HSIL

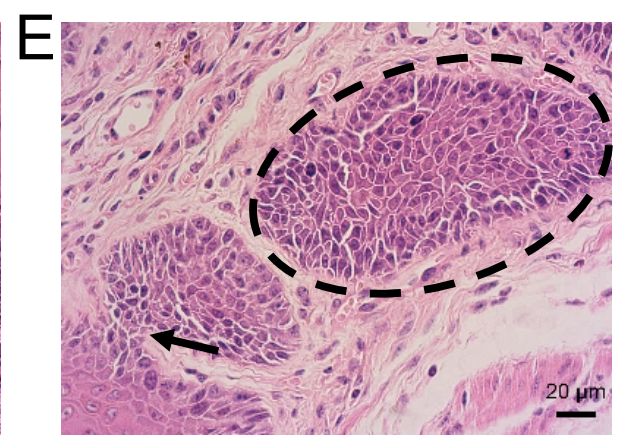

SCC

\section{Nuclear-to-cytoplasmic ratio}

Figure 2. Squamous intraepithelial lesions and squamous cell carcinoma in AKP mice. (A) Schematic timeline of the progression of squamous intraepithelial lesions to squamous cell carcinoma in AKP mice. At 8 weeks, (B) $\mathrm{Pgr}^{+++}$vagina showed normal stratified squamous epithelium (SSE). (C) Ten percent of AKP vaginas contained LSIL with increased nuclear-to-cytoplasmic ratios and loss of maturation (LOM) in the lower epithelium. (D) Seventy percent of AKP vaginas exhibited HSIL with cell crowding, high nuclear-to cytoplasmic ratio, and LOM in at least two-thirds of the epithelium. (E) Twenty percent of AKP vaginas displayed squamous cell carcinoma with nests of cells (dashed circle) and highly dysplastic squamous epithelium invading through the stroma (black arrow). Scale bars, $20 \mu \mathrm{m}$. Hematoxylin and eosin staining. 

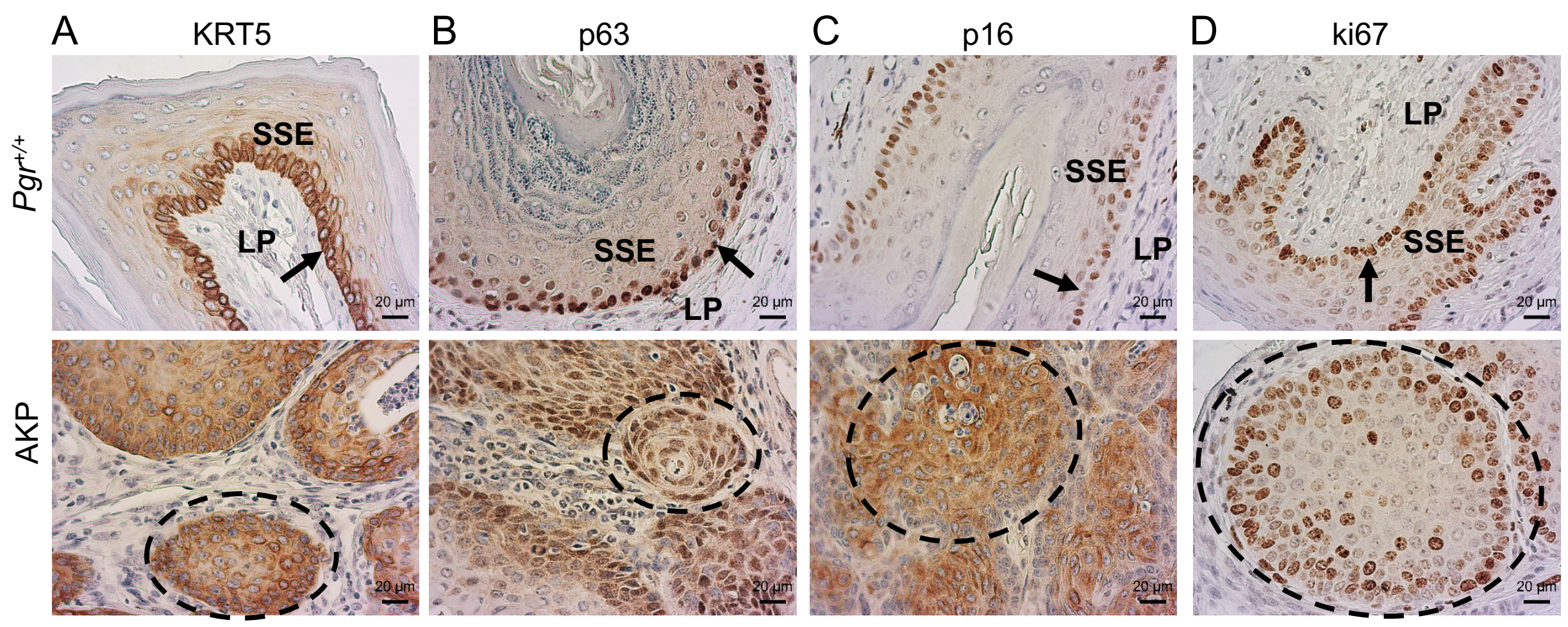

Figure 3. Molecular Immunohistochemical staining for (A) cytokeratin 5 (KRT5), (B) tumor protein P63 (p63), (C) cyclin dependent kinase inhibitor 2A ( $p 16)$, and (D) marker of proliferation Ki-67 (ki67). SSE = stratified squamous epithelium, LP = lamina propria, arrow $=$ basal layer, dashed circle $=$ nests of squamous cell carcinoma. Scale bars, $20 \mu \mathrm{m}$. 

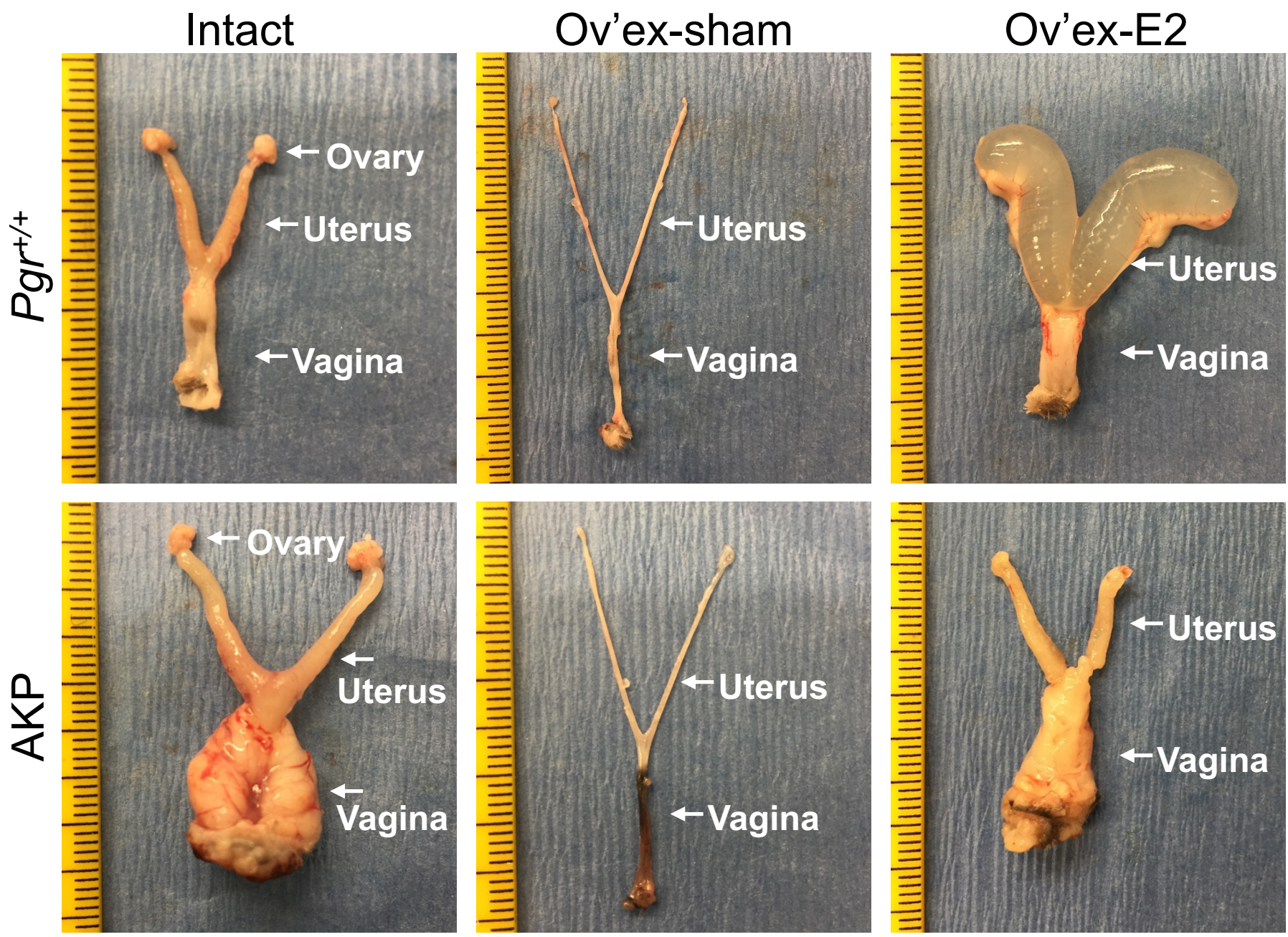

Figure 4. Gross lesions in AKP mice with $17 \beta$-estradiol treatment for 60 days. Intact AKP mice exhibited large gross vaginal lesions. Both ov'ex $\mathrm{Pgr}^{+/+}$-sham and ov'ex AKP-sham mice exhibited tiny, thin uteri without gross vaginal lesions. Ov'ex $\mathrm{Pgr}^{++}-\mathrm{E} 2$ mice had enlarged fluid-filled uteri. Ov'ex AKP-E2 mice exhibited gross vaginal lesions but without the edematous cystic nature of the uterus. Ruler, tick mark indicates $1 \mathrm{~mm}$. 
Intact

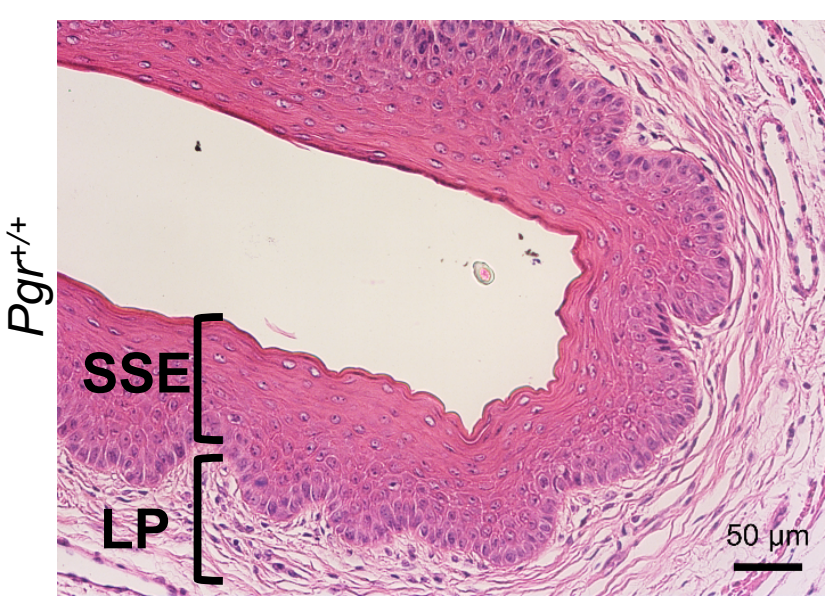

$\frac{0}{4}$

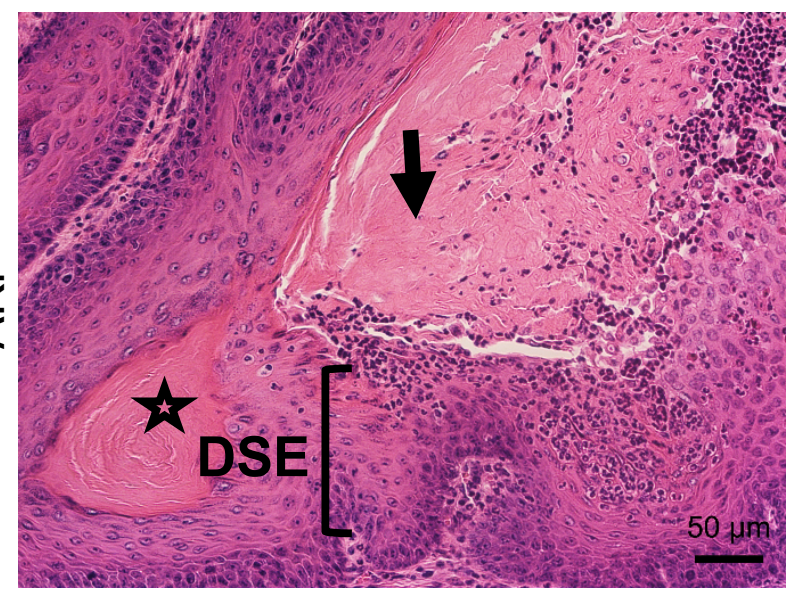

Ov'ex - sham
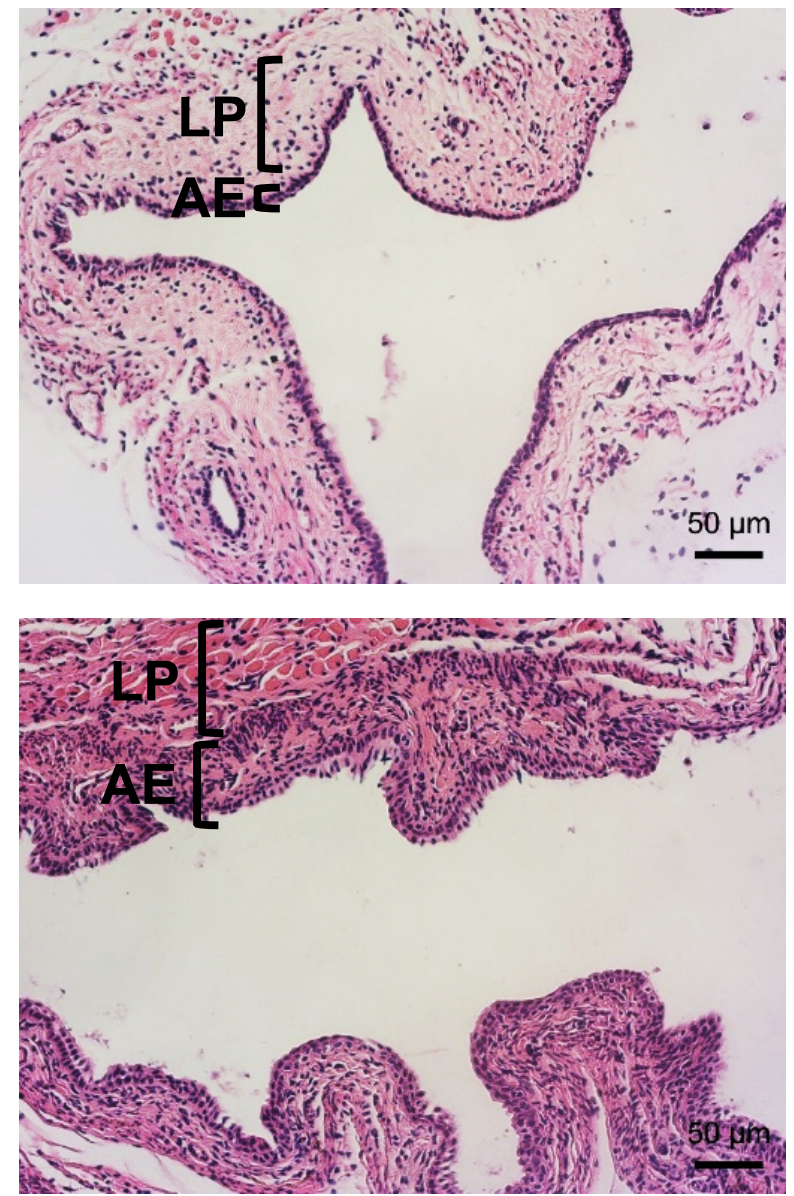

Ov'ex - E2
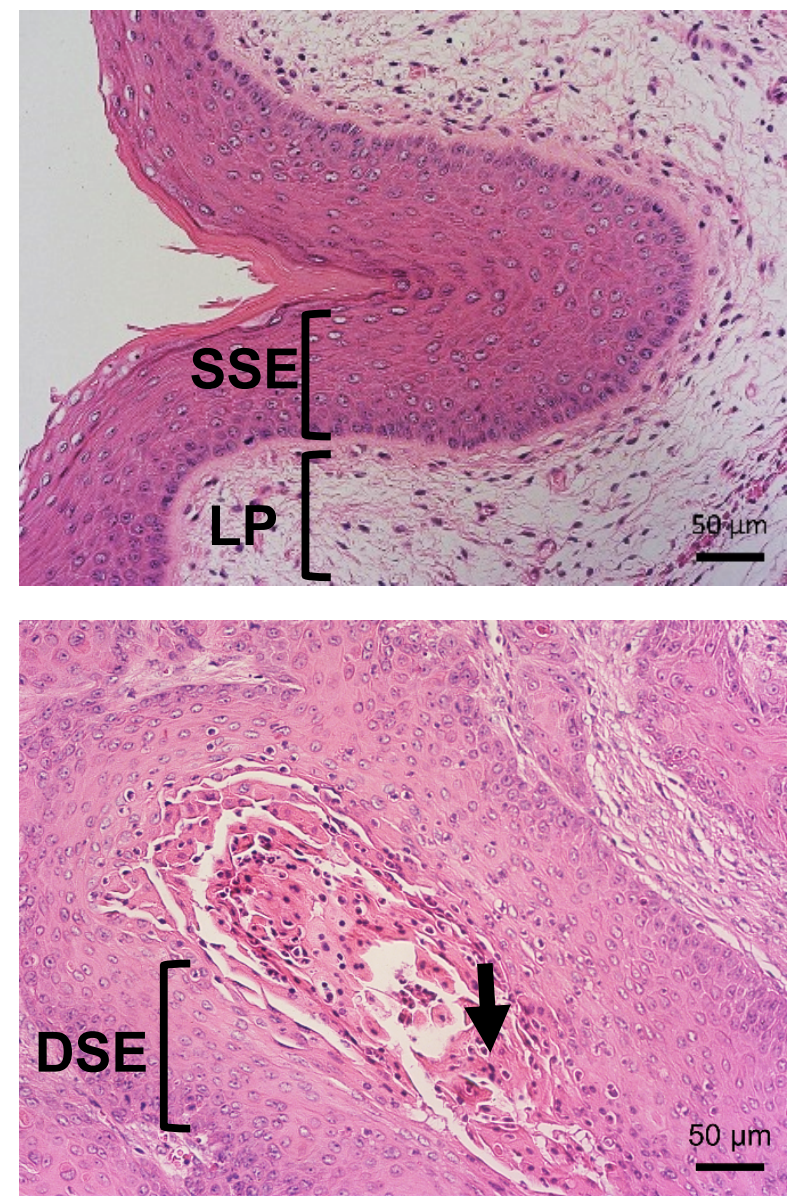

Figure 6. Vaginal histology in $\mathrm{Pgr}^{+/+}$and AKP mice with and without $17 \beta$-estradiol (E2) treatment.16-week-old intact $P g r^{+/+}$and AKP mouse vaginas are shown for comparison. Intact $\mathrm{Pgr}^{+/+}$vaginas exhibited normal keratinized stratified squamous epithelium (SSE) with underlying lamina propria (LP). Intact AKP vaginas show squamous cell carcinoma with central keratinization (star), eosinophilic cytoplasm (arrow), and dysplastic squamous epithelium (DSE). Ov'ex $\mathrm{Pgr}^{+/+}$-sham vaginas exhibited signs of vaginal atrophy with thin atrophic epithelium (AE) and thin lamina propria. Hormone replacement resulted in a thickened epithelial layer with keratinization and normal lamina propria. Ov'ex AKP-sham mice exhibited thinning of vaginal epithelium without evidence of carcinoma. Ov'ex AKP-E2 mice exhibited squamous cell carcinoma with dysplastic squamous epithelium (DSE) and eosinophilic cytoplasm (black arrow). Scale bars, $50 \mu \mathrm{m}$. Hematoxylin and eosin staining. 